\title{
O CUIDADO MATERNO NO MANEJO DA ASMA INFANTIL - CONTRIBUIÇÃO DA ENFERMAGEM TRANSCULTURAL
}

\author{
Maternal Care in the Management of Child Asthma: the \\ Contributions of Transcultural Nursing
}

\section{El Cuidado Materno en el Manejo del Asma Infantil - Contribución de Enfermería Transcultural}

\section{RESUMO}

0 objeto deste estudo são as práticas culturais do cuidado materno no manejo da asma infantil. Objetivos: descrever 0 conhecimento e o cuidado materno sobre a asma infantil e analisar o cuidado materno no manejo da asma infantil. Estudo descritivo-exploratório desenvolvido a partir de questionários e entrevistas com mães de crianças com asma, no período de setembro de 2008 janeiro de 2009. Após análise temática dos dados, emergiram três categorias: 1) Conceito e manejo da asma na visão das mães cuidadoras; 2) Asma como sofrimento e risco para a vida dos filhos; 3) Plantas medicinais, simpatias e religiosidade no cuidado do filho com asma. Concluiu-se que é importante respeitarmos a cultura das mães cuidadoras das crianças com asma, para que seus valores possam ser preservados, acomodados e reestruturados junto ao cuidado profissional. Palavras-chave: Saúde da Criança. Enfermagem Transcultural. Enfermagem Pediátrica. Cuidado da Criança. Asma.

Palavras-chave: Saúde da Criança. Enfermagem Pediátrica. Oncologia. Filosofia em Enfermagem. Existencialismo.

\begin{abstract}
The object of this study is the cultural practices of maternal care in the management of childhood asthma. Objectives: to describe both maternal knowledge and care of child asthma and to analyze maternal care in the management of child asthma. This is an exploratory descriptive study developed with the use of questionnaires and interviews with mothers of asthmatic children from September 2008 to January 2009. After thematic analysis of data, three categories emerged: 1) The concept of asthma and its management in the eyes of caretaker mothers, 2) Asthma both as a suffering and a risk to children's lives, 3) Medicinal plants, simpathies and religiosity in the care of asthmatic children. The results have shown that it is important to respect the culture of caretaker mothers of children with asthma, so that their beliefs can be preserved, accommodated and restructured with professional care.
\end{abstract}

Keywords: Child health. Transcultural nursing. Pediatric nursing. Child care. Asthma.

\section{Resumen}

El objeto de este estudio es analizar las prácticas culturales de la atención materna en el manejo del asma infantil. Objetivos: describir el conocimiento y el cuidado de la madre en relación con el asma infantil y analizar la atención materna en el manejo del asma infantil. Estudio exploratorio-descriptivo desarrollado a partir de cuestionarios y entrevistas con madres de niños con asma, en el período comprendido entre Septiembre de 2008 y Enero del 2009. Tras el análisis temático de los datos, surgieron tres categorías: 1) Concepto y manejo del asma en la visión de las madres que cuidan de sus hijos con asma, 2) El asma como sufrimiento y riesgo para la vida de los hijos, 3) Plantas medicinales, rituales y religiosidad en el cuidado del hijo con asma. Se concluyó que es importante respetar la cultura de las madres que cuidan de los niños con asma, de modo que sus valores puedan ser preservados, acomodados y reestructurados junto a la atención profesional.

Palabras clave: Salud del niño. Enfermería transcultural. Enfermería pediátrica. Cuidado del niño. Asma.

'Graduanda em Enfermagem pela Escola de Enfermagem Alfredo Pinto (EEAP) da Universidade Federal do Estado do Rio de Janeiro (UNIRIO). Bolsista de Iniciação Científica/UNIRIO, membro do Grupo de Pesquisa "Núcleo de Pesquisa, Experimentação e Estudos em Enfermagem na Área da Mulher e da Criança - NuPEEMC". Brasil. Email: mairinhadbs@hotmail.com, ² Doutora em Enfermagem na Área da Saúde da Mulher; Professora Adjunta do Departamento de Enfermagem Materno-Infantil (DEMI)/EEAP/UNIRIO. Brasil. Email: rangel.leila@gmail.com , 3Professora Adjunta do DEMI/EEAP/UNIRI0. Doutoranda da EEAN/UFRJ. Brasil. Email: inesmeneses@gmail.com 


\section{INTRODUCÃO}

0 objeto deste estudo são as práticas culturais do cuidado materno no manejo da asma infantil. A asma brônquica é definida como uma forma de alergia respiratória, onde há uma inflamação crônica caracterizada por hiper-responsividade das vias aéreas inferiores e por limitação variável ao fluxo aéreo, reversível espontaneamente ou com tratamento. A fase preventiva é relevante em razão das recidivas das crises asmáticas.

De acordo com a Iniciativa Global para a Asma (GINA), que trabalha com profissionais de saúde e agentes comunitários da saúde pública em todo o mundo para reduzir a prevalência, morbilidade e mortalidade à asma, esta é uma das doenças crônicas mais comuns no mundo. Estima-se que cerca de 300 milhões de pessoas em todo o mundo têm asma. ${ }^{2}$

No Brasil, ocorreram 205.305 internações por asma, com um impacto importante na faixa etária pediátrica, sendo internadas cerca de 100.000 crianças menores de 14 anos com o diagnóstico de asma no Sistema Único de Saúde (SUS) no ano de $2008,{ }^{3}$ o que torna importante considerar a subnotificação da doença no país.

0 Ministério da Saúde, em 13 de dezembro de 1999, promulgou a Portaria 1394, que implantou o Programa Nacional de Controle a Asma (PNCA), em colaboração com as Sociedades Brasileiras de Especialidades (Pneumologia e Tisiologia, Pediatria, Alergia e Imunopatologia e Clínica Médica). 0 PNCA tem a finalidade de organizar, implantar e manter a assistência dos pacientes asmáticos por intermédio do SUS, utilizando para isto tanto os recursos próprios dos locais de assistência, quanto os provenientes do Ministério da Saúde. ${ }^{1}$

Os mais fortes fatores de risco para o desenvolvimento de asma são uma combinação da predisposição genética com a exposição ambiental da inalação de substâncias e partículas que podem provocar reações alérgicas ou irritar as vias respiratórias, tais como: alérgenos internos (por exemplo, os ácaros em casa, cama, tapetes, poluição), alérgenos externos (como polens), fumo do tabaco, irritantes químicos, a poluição do ar, ar frio, extrema excitação emocional como a raiva ou medo, e exercício físico. ${ }^{4}$

Essa doença pode levar a sérios problemas tanto para a criança como para os familiares, pois, por existir um caráter hereditário, pode haver a culpabilização nos pais por terem transmitido a asma ao seu filho. Há também a necessidade de adaptação no ambiente domiciliar, por ser a higiene uma medida de prevenção, como retirada de cortinas, animais domésticos, sofás estofados, entre outros.

Todo enfermeiro envolvido com o cuidado de crianças tem de praticar a saúde preventiva, e a melhor forma de abordagem é a orientação e educação para a saúde. ${ }^{5}$ A educação como tarefa teórico/prática se caracteriza por uma relação de aprendizagem em que não existem o "educador que ensina" e a "população que aprende", mas sim um grupo que, por meio do trabalho e da reflexão, vai produzindo seu próprio conhecimento, e vai aprendendo a conhecer, a partir da realidade objetiva sentida. É um processo de construção de um saber coletivo, apontando as possibilidades de intervenção e de transformação dessa realidade, pois o comportamento do homem depende das suas crenças, isto é, daquilo que ele supõe que seja a verdade. ${ }^{6}$

A infância é uma fase da vida na qual o indivíduo não tem independência no autocuidado, sendo a mãe, na maioria das vezes, a cuidadora. Nessa pesquisa, optou-se por falar sobre o cuidado materno visto que o papel da mãe é fundamental no manejo e tratamento da asma. Quando a sociedade se interessa pela criança, por sua sobrevivência e educação, o foco é apontado para a mãe, que se torna personagem essencial, em detrimento do pai.?

Os questionamentos para esta investigação surgem em relacionar as recidivas da asma infantil com o conhecimento dessas mães sobre a patologia, o cuidado cultural e as ações que são realizadas por elas na prevenção.

Durante as consultas de enfermagem pediátrica/ puericultura, e até mesmo nas salas de espera que realizávamos enquanto as mães aguardavam atendimento, surgiram algumas "dificuldades" de interação/comunicação mais efetiva entre o profissional de saúde e cliente, por não conhecermos a realidade cultural e o meio em que a criança está inserida para que possamos ajustar nossas orientações a partir da realidade do ambiente em que vivem.

A cultura consiste em um padrão de suposições, crenças e práticas que inconscientemente moldam ou guiam a perspectiva e as decisões de um grupo de pessoas. Nesse sentido, torna-se complexo conceituar a cultura, em razão desta representar uma teia de significados a serem interpretados. ${ }^{8}$ Os enfermeiros são desafiados a desenvolver a dinâmica da sensibilidade cultural, uma consciência das semelhanças e diferenças culturais. ${ }^{9}$

Todas as culturas desenvolvem rituais de cuidados, porém isso não ocorre da mesma forma em todas as culturas. Assim, alguns rituais são mais significantes e terapêuticos do que outros, mas sempre têm propósitos ou funções específicos para as culturas. As crenças, valores e normas de cuidados têm importante influência na sobrevivência humana, no crescimento, desenvolvimento e no processo saúde e doença. Ocorrem dois sistemas de cuidado à saúde: o popular e 0 profissional, entre os quais existem valores e práticas próprios, podendo ocorrer divergências deles em algumas comunidades. ${ }^{9}$

Para a enfermeira e antropóloga Madeleine Leininger, 0 cuidado humano é universal, sendo experimentado, diferentemente, nas diversas culturas, e, em sua Teoria do Cuidado Cultural (TCC), sobre a Diversidade e Universalidade, preconiza que o conhecimento do mesmo é necessário para o desenvolvimento da prática assistencial de enfermagem de maneira satisfatória e humanística. Cunhou o termo cuidado culturalmente congruente para embasar o principal objetivo de sua Teoria: "identificar os meios para proporcionar um 
cuidado de enfermagem culturalmente congruente aos fatores que influenciam a saúde, o bem-estar, a doença e a morte das pessoas de culturas diversas e semelhantes". ${ }^{9}$

Os estudos realizados e publicados na área da enfermagem abordando a temática cuidado materno diante da asma infantil são escassos, o que chamou a atenção, considerando as estatísticas tão altas acerca da incidência da asma no Brasil.

Em pesquisa realizada nos periódicos indexados na base de dados SciELO (Scientific Electronic Library Online) no período de 1999 a 2008, foram encontrados quatro estudos utilizando os termos Asma e Enfermagem como descritores. Foi encontrado um estudo sobre a frequência de publicações sobre a asma em periódicos de enfermagem indexados em bases de dados brasileiros que tiveram como metodologia a coleta de dados por meio de formulário, utilizando-se os descritores de assunto asthmae asma para busca das produções onde foram identificados 56 artigos internacionais e três nacionais nos anos de 1994 a 2004; foi apontada a necessidade de maior produção e/ou divulgação do conhecimento produzido, principalmente em publicações brasileiras. $^{10}$

Seguindo essas reflexões, consideraram-se como fundamental para o direcionamento do estudo as seguintes questões norteadoras: 0 que as mães sabem sobre a doença e quais são os cuidados maternos que são utilizados no manejo da asma do filho? De que forma os aspectos culturais influenciam no cuidado materno à asma infantil?

Com base nessas considerações, os objetivos deste estudo foram descrever o conhecimento e o cuidado maternos sobre a asma infantil e analisar o cuidado materno no manejo da asma infantil.

Diante da necessidade de perceber e compreender a diversidade das atitudes das mães que se encontram em processo de cuidar do filho portador de asma, a Teoria do Cuidado Cultural (TCC) fornece aos profissionais de saúde, e em especial aos enfermeiros, subsídios para a busca de maneiras de cuidar apoiadas em modelo de preservação da identidade cultural materna. Sabe-se que um dos principais pilares no manejo da asma diz respeito ao processo educativo, com isso, faz-se necessário conhecer as características socioculturais das mães que cuidam de filhos com asma para que se possa adaptar o cuidado profissional, respeitando a cultura da comunidade; dessa forma, obter-se-á uma resposta satisfatória.

Na perspectiva de incentivar a prevenção da crise e promover a saúde dessas crianças, tornamo-nos responsáveis por pesquisar sobre o cuidado cultural materno na asma infantil, com o intuito de colaborar na melhoria da qualidade de vida dessa população.

No tocante à assistência e pesquisa em enfermagem, o estudo oferece subsídios para a busca de melhores maneiras de manejar a asma entendendo que a cultura influencia todas as dimensões do ser, tanto o corpo que cuida como o que recebe o cuidado, contribuindo para a ampliação do conhecimento sobre a temática. Destaca-se que esta pesquisa vem ao encontro dos estudos desenvolvidos pelo Núcleo de Pesquisa, Estudos e Experimentação na Área da Saúde da Mulher e da Criança (NuPEEMC) EEAP/UNIRIO.

\section{REFERENCIAL TEÓRICO \\ A Teoria do Cuidado Cultural (TCC) de Madeleine Leininger}

Para cuidarmos da saúde do ser humano não devemos somente nos restringir ao modelo biomédico pautado nos conceitos de prevenção, diagnóstico, tratamento e reabilitação. É imperioso que os profissionais de saúde, entre eles os profissionais de enfermagem, comecem a conhecer o contexto cultural, os valores e crenças das mães que cuidam de crianças com asma. Esta foi uma investigação sobre as práticas populares do cuidado materno diante da asma infantil, com o referencial da TCC.

A teórica estabeleceu alguns pressupostos que são ideias que antecedem à formulação de conceitos, ou seja, são crenças e valores claramente enunciados, ${ }^{11}$ como:

- $\quad 0$ cuidado (cuidar) é essencial ao curar, pois não pode haver cura sem cuidado. ${ }^{12}$

- $\quad$ Os conceitos, significados, expressões, padrões, processos e formas estruturais de cuidado cultural são diferentes (diversidade) e similares (universalidade) entre todas as culturas do mundo. ${ }^{12}$

- $\quad$ Todas as culturas humanas têm conhecimentos e práticas de cuidado cultural genérico (leigo, popular ou nativo) e, em termos gerais, conhecimentos e práticas de cuidado profissional que variam transculturalmente. ${ }^{12}$

Esses pressupostos são a mola propulsora das três grandes ações que servem para guiar as decisões ou ações de enfermagem na TCC.

PRESERVAÇÃO ou MANUTENÇÃO DO CUIDADO CULTURAL inclui as ações e decisões profissionais que ajudam as pessoas de uma determinada cultura reter e/ou preservar valores relevantes de cuidados, de forma que possam manter seu bemestar, recuperar-se da doença ou encarar as deficiências e/ou morte. ${ }^{12}$

ACOMODAÇÃO ou NEGOCIAÇÃO DO CUIDADO CULTURAL inclui as ações e decisões profissionais que ajudam as pessoas de uma determinada cultura a adaptar-se ou a negociar com as outras um resultado de saúde benéfico ou satisfatório com prestadores de cuidados profissionais. ${ }^{12}$

REPADRONIZAÇÃO ou REESTRUTURAÇÃO DO CUIDADO CULTURAL inclui as ações e decisões profissionais que ajudam o cliente a reorganizar, trocar ou modificar sua forma de vida para um padrão de atendimento de saúde novo, diferente e benéfico, enquanto são respeitados os valores culturais e as crenças do cliente, proporcionando um modo de vida mais saudável que 0 anterior. ${ }^{12}$ 


\section{ABORDAGEM METODOLÓGICA}

Trata-se de um estudo descritivo-exploratório. 0 campo de investigação foi o ambulatório pediátrico de um hospital geral situado no estado do Rio de Janeiro. A fim de garantir o cumprimento das questões éticas, o estudo foi aprovado, sem restrições, pelo Comitê de Ética em Pesquisa da Escola de Enfermagem Anna Nery/Hospital Escola São Francisco de Assis (CEP EEAN/HESFA), protocolo número 60/08, considerandose o que prevê a Resolução n ${ }^{0}$ 196/96 ${ }^{13}$. Ressalta-se que todos os sujeitos foram informados sobre a justificativa, os objetivos e a metodologia do estudo. Após receberem todos os esclarecimentos pertinentes ao estudo, as depoentes assinaram o Termo de Consentimento Livre e Esclarecido.

Participaram do estudo 18 depoentes que compareceram ao Ambulatório Pediátrico, no período de setembro de 2008 a janeiro de 2009 e que se adequaram aos critérios da inclusão delimitados: mães de filho portador de asma com pelo menos seis meses de diagnóstico da doença e que aceitassem participar da pesquisa. 0 tempo mínimo de seis meses foi escolhido, pois este é um intervalo de tempo suficiente para que a mãe já possa relatar como é cuidar de uma criança com asma.

Vale destacar que a quantidade de mães-depoentes foi determinada após a obtenção do ponto da saturação. A saturação refere-se a recolher as ocorrências e significados, e quando há uma redundância de informações, nas quais o pesquisador consegue a mesma informação em vários momentos e as depoentes não têm mais nada a oferecer, pois disseram e compartilharam tudo. ${ }^{12}$

Para a produção dos dados, foram utilizados um questionário com perguntas fechadas que versavam sobre a identificação e caracterização socioeconômica dos sujeitos e uma entrevista semiestruturada que foi gravada em fitas magnéticas (K7), cujo roteiro foi constituído de questões abertas que favoreceram a análise dos cuidado materno diante da asma infantil a fim de contemplar os objetivos do estudo.

A análise qualitativa seguiu o Método da Etnoenfermagem de Leininger ${ }^{12}$, que utiliza quatro fases específicas da análise de dados relacionados ao tema, objetivos ou questões do estudo, alcançados pelo pesquisador. A primeira é conhecida como relação dos dados coletados. Nesse momento, as pesquisadoras reúnem todo o material da coleta para uma primeira leitura, enquanto a segunda fase - identificação dos descritores e seus componentes - foi o momento de caracterizar as falas das informantes, com o objetivo de identificar as semelhanças e diferenças quanto às afirmações e comportamentos encontrados. Na terceira fase de análise do padrão contextual, foi realizada avaliação criteriosa dos dados, com a finalidade da saturação de categorias para demonstrar os padrões do cuidado com respeito aos significados no contexto, consistência e credibilidade; por fim, houve a fase denominada temas principais, em que se discutiram as descobertas da pesquisa.
Foram codificadas três categorias analíticas: 1) Conceito e manejo da asma na visão das mães cuidadoras; 2) Asma como sofrimento e risco para a vida dos filhos; 3) Plantas medicinais, simpatias e religiosidade no cuidado do filho com asma.

\section{ANÁLISE E DISCUSSÃO DOS RESULTADOS DE PESQUISA}

\section{Perfil dos sujeitos do estudo}

Foi traçado o perfil das mães cuidadoras dos filhos com asma para facilitar a compreensão cultural do grupo em estudo. A construção do perfil sociodemográfico reflete mais que apenas o ambiente que rodeia a criança e a mãe, reflete também um conjunto de necessidades, as quais nos dão suporte para um olhar cultural.

Com relação à faixa etária, encontramos mães com idade entre 21 e 49 anos. As crianças com asma estão entre a faixa etária de 2 e 15 anos, sendo 7 do sexo feminino e 11 do sexo masculino.

Do estado civil das 18 mães, predominam as casadas (13); no entanto, mesmo com o pai próximo à criança, a mãe, na maioria das vezes, referiu ser a responsável pelo cuidado da criança. As mães, em sua maioria (14), não trabalham e relataram ficar a maior parte do seu tempo com os filhos. As profissões das trabalhadoras (4) são: técnica de enfermagem, digitadora, manicure, professora.

Quanto a escolaridade, 6 têm o ensino médio completo; 5, ensino médio incompleto; 2 ensino fundamental incompleto; 1 , ensino fundamental completo; 2 ensino superior incompleto; $\mathrm{e}$ 2 , ensino superior completo. Sendo que a maioria tem renda familiar de 2 a 3 salários mínimos (7). Nota-se que, com a falta de estudos completos, para a maioria das mães, espelha a problemática socioeconômica em que se encontram.

I- CONCEITO E MANEJO DA ASMA NA VISÃO DAS MÃES CUIDADORAS

De acordo com os depoimentos, constatamos que muitas mães desconhecem ou são inseguras quando questionadas sobre o conceito/significado da asma, o que nos faz acreditar que há falta de informações/orientações por parte dos profissionais de saúde e um serviço de educação em saúde conforme relatos de Flor de Lis e Orquídea.

[...] Não sei bem o que é a asma. Não sei falar o que é não, só sei que uma coisa que, não sei explicar [...] (Flor de Lis)

[...] Quase nada! O que eu sei da asma é que não pode ter gato, cachorro, bicho de pelúcia, é a única coisa que eu sei. Fica sem respirar [...] (Orquídea)

Muitas mães não sabem o significado de prevenção e confundem esta com tratamento da doença. A partir do questionamento sobre o que elas fazem para prevenção da 
Cuidado Materno no Manejo da Asma Infantil

Silva MDB, Silva LR, Santos IMM

crise de asma de seus filhos, destacamos as falas de Jasmin e Dália.

$$
\begin{aligned}
& \text { [...] Eu faço uso de berotec spray [...] (Jasmin) } \\
& \text { [...] O que eu mais faço é nebulização e muito soro } \\
& \text { para lavar bem [...] (Dália) }
\end{aligned}
$$

Cabe destacar que muitas mulheres falaram do cuidado do ambiente, e isso nos mostra que, mesmo não sabendo conceituar a asma, sabem prevenir as crises da doença, como podemos ilustrar no depoimento de Hortência

[...] Os animais que ela tinha, ela tinha coelho, tinha cachorro grande peludo e eu troquei por um pinscher, que é um cachorro de pequeno porte com a pelagem rasteira [..]. (Hortência)

Observa-se também que as mães superprotegem seus filhos com medo de novas crises de asma, impondo limites às atividades desenvolvidas pelas crianças, o que pode prejudicar no desenvolvimento normal delas. Em um estudo, foi constatado por meio dos discursos, que a mãe da criança asmática, com medo do aparecimento de novas crises, superprotege o filho, impedindo-o, assim, de levar uma vida normal, o que pode retardar seu desenvolvimento natural. ${ }^{14}$ Merece destaque 0 discurso de Lírio:

$$
\begin{aligned}
& \text { [...] Eu tirei tudo. Lá em casa não tem nada, cortina, } \\
& \text { não tem nada, por causa do meu filho [...] (Lírio) }
\end{aligned}
$$

Fica evidente a falta de conhecimento das mães sobre o conceito da asma, e faz-se necessária a implantação de serviços de educação em saúde, com atendimento integral e realização de capacitação/treinamento/workshop para instrumentalizar os profissionais de saúde para trabalharem com grupos educativos permanentes nas Instituições Ambulatoriais e Hospitalares.

\section{II- ASMA COMO SOFRIMENTO E PERIGO PARA A VIDA DOS FILHOS}

As mães desenvolvem sofrimento durante os períodos de crise relatando o medo da perda dos filhos, associando esta doença a um risco de morte, conforme relato de Rosa vermelha e Jasmin.

[...] Com sinceridade, sinceridade, eu já associei ela, assim, como é que eu posso te dizer, a um perigo para mim [...] (Rosa Vermelha)

[...] É a pior doença que existe na vida. É um sofrimento ruim mesmo [...] (Jasmin)

0 sofrimento e a ansiedade materna andam juntos e, provavelmente, são decorrência das características da asma em sua imprecisão, labilidade e seu aparecimento inopinado, levando a mãe ao estado de suspensão de expectativas e à paralisação de toda a possibilidade de antecipação, abrindo a porta para emergência do inconsciente. ${ }^{15}$

III- PLANTAS MEDICINAIS, SIMPATIAS E RELIGIOSIDADE NO CUIDADO DO FILHO COM ASMA

Apesar de as mães relatarem desconhecimento e insegurança no cuidado do filho com asma, todas utilizam o saber popular como a utilização de plantas medicinais do tipo xarope. Há também simpatias e crenças religiosas que são perpetuadas de geração para geração de forma independente, sendo produzidos e reproduzidos de forma empírica. Assim, constatamos a importância do cuidado cultural materno quando nos deparamos com o depoimento de Crisântemo, que nos informa que fazem xaropes para asma utilizando legumes e glicose:

[... Me ensinaram a fazer tanto com nabo quanto com beterraba e cebola, cortar em rodelas, colocar num prato e colocar açúcar por cima e deixar no sereno, da noite pro dia, e quando for antes das 6 da manha, retirar e dar em colheradas para as crianças, fica em forma de xarope [...] (Crisântemo)

Os saberes naturais dessas mães, nos cuidados aos seus filhos com asma, são transmitidos por herança familiar e pelas relações de vizinhança. Algumas mulheres relatam que utilizam simpatias que aprenderam com suas avós; por exemplo, Lírio nos informa que:

[...] Faço xarope caseiro também, tudo de erva. Minha avó me ensinou [...] (Lírio)

Muitas das informantes procuraram não exteriorizar muitos dos cuidados desempenhados, pois dizem que não podem ensinar a simpatia, visto que não ocorreria efeito para o filho conforme depoimento de Girassol:

[...] E outra coisa, simpatia não pode contar quando faz. Se contar pode não ter efeito [...] (Girassol)

Muitas mães informaram que não têm crenças e fazem simpatias para melhora das crises de asma; entretanto, fazem xarope com ervas medicinais para aliviar os sinais e sintomas,; destacamos o relato de Copo de Leite.

[...] Eu nunca fiz simpatia não porque eu não acredito. Aí o que que eu faço?! Eu dou xarope natural pra ela, eu coloco hortelã, aí tem um tal de assa peixe, é tudo ervas [...] (Copo de Leite)

A fé na cura da doença do filho foi muito expressada, conforme podemos ler no depoimento de Girassol:

[...] Porque quem cura é Deus e a fé que a gente tem. Não é aquilo que você tá fazendo. Se você tem 
fé, você pode tomar um copo de água que vai ficar bom [...] (Girassol)

0 uso de estratégias espirituais de enfrentamento pode aumentar o autofortalecimento, levando o paciente à busca do significado e do propósito na enfermidade. Isto implica dizer que o cuidado holístico incorpora a facilidade de várias estratégias espirituais de enfrentamento para a proteção e a total integridade dos pacientes. ${ }^{16}$

Quando o paciente procura um serviço de saúde, é o momento ideal para que haja a troca de informações. É importante que o enfermeiro e outros profissionais de saúde saibam ouvir a história da mãe para com isso construírem juntos um melhor cuidado para a criança com asma. A saúde e a doença permeiam todo o processo de viver, e a participação e interação das mães-cuidadoras de filhos com diagnóstico de asma precisam ser diferenciadas quanto ao manejo da asma pelo profissional de saúde. Esse processo é organizado culturalmente por meio dos rituais de cuidado ${ }^{17}$.

[...] Nem sempre é possível fazer, ter o cuidado que às vezes os médicos pedem pra gente, fica inviável, não tem como [...] (Hortência)

A fala de Hortência nos mostra a necessidade de ouvirmos os nossos clientes, conhecer os modos de vida, as condições do ambiente e financeira, já que temos a responsabilidade de prestar uma assistência/orientação de qualidade e suporte, e habilitar ou facilitar individualmente, ou em grupo, a melhoria da condição de saúde. Leininger, ao falar de cuidar em enfermagem, sempre menciona a importância de utilizar, além da teoria e da técnica, o ouvir, o observar, o sentir e ainda o socializar os saberes, para, desse modo, respeitar as experiências e individualidade de quem está sendo cuidado.

\section{Ações da Enfermagem na Teoria do Cuidado Cultural (TCC)}

Ao final dos depoimentos maternos, foi necessária uma troca de informações com as mães acerca dos seus conhecimentos sobre a asma e das ações para o manejo desta doença; valorizou-se neste momento, as três formas de atuação do profissional de saúde: manutenção, negociação e reestruturação do cuidado cultural. ${ }^{9}$

Em relação à preservação do cuidado cultural, é importante considerarmos, a partir deste estudo, que as crenças religiosas, os valores culturais e o modo de vida devem ser preservados e encorajados no cuidado da mãe ao seu filho portador de asma. É importante também preservar o uso de ervas e plantas medicinais em seus cuidados. Nesta ação de enfermagem, a identidade cultural das mães pode ser trabalhada com as enfermeiras para buscar a congruência e compreensão da sua prática, pois, ao manter as ações do sistema popular, acreditase que estas proporcionam bem-estar e que se apresentam como mecanismos de enfrentamento apreendidos de como conviver com um filho portador de asma.
Em relação à acomodação (negociação) do cuidado cultural, neste estudo nota-se que, embora as mães tenham os seus saberes para cuidarem de seus filhos, é importante a negociação do cuidado em alguns aspectos, como a diminuição da exposição a poeiras, fumaça de cigarro e cheiros fortes, como perfumes, pela criança, para que, ao evitar o contato com estimulantes, não tenha tanta recidivas das crises de asma. Foi negociado com as mães que é importante a procura pelo serviço de saúde mesmo com a continuidade das orações. As ações negociadas demandam do sistema popular e também do sistema profissional. Seria importante que os profissionais de saúde, em especial os enfermeiros, continuassem a praticar a acomodação do cuidado cultural realizando ações congruentes com as necessidades das mães que se refletem em suas crenças e valores culturais.

A repadronização do cuidado cultural foi proposta às mães como forma de revisão quanto aos pontos negativos da fumaça de cigarro perto dos filhos, bichinhos de pelúcia no quarto, umidade/mofo na casa; após a revisão, as mães afirmaram que cuidariam mais ativamente desses pontos ligados ao ambiente em que a criança estaria exposta. Assim, respeitamos as crenças das mães, e não a impedimos de ter animais domésticos, móveis estofados e cortinas, por exemplo, se assim deseja, mas buscamos, repadronizar o hábito da cliente, introduzindo em sua cultura o conhecimento dos malefícios dessa prática. Todavia, precisamos entender que, na tentativa de repadronizar uma cultura, é necessário que se argumente sobre as vantagens e desvantagens de tal prática, para que haja uma motivação da mãe em manter ou se adaptar a um novo modo de vida. 0 enfermeiro deve articular o cuidado mediante a identificação do cuidado popular e o conhecimento do cuidado profissional.

\section{CONSIDERACÕES FINAIS}

0 contato com as mães ao longo deste estudo demonstrou que a sua prática está pautada nos saberes que são perpetuados tanto de geração a geração, como pelas vizinhanças, e também em atitudes que diferem sensivelmente da medicina tradicional, pautada no modelo intervencionista, técnico e biomédico. Diante disso, foi possível distinguir o cuidado profissional do cuidado popular. Entretanto, percebe-se que os profissionais de saúde, entre eles os profissionais de enfermagem, precisam conhecer e entender sobre a cultura da clientela, pois esta interfere no processo de cuidar, e, de acordo com Leininger, o cuidar é a essência da Enfermagem. ${ }^{12}$

As práticas do cuidado materno na asma infantil incluem o uso de diversas crendices, rituais e religião, além dos mais variados tipos de plantas medicinais, frutos e legumes. Foi evidenciado nos depoimentos que a maioria de seus saberes é construída por intermédio da fé, por meios das orações e do uso de simpatias. Houve relatos de que as simpatias não podem ser reveladas para não desfazer o efeito da cura na asma da criança. 
É preciso deixar claro que não negamos o valor da ciência, como também não afirmamos que as práticas culturais das mães sejam mais eficazes que a medicina tradicional e que esses cuidados garantam a saúde dessas crianças sem as práticas das instituições de saúde. Na verdade, a intenção é fazer com que a enfermagem tenha uma visão holística dos saberes e crendices que permeiam o cuidado materno diante da asma infantil.

Não basta o profissional ser cientifico. Ele deve ser humano, produzir saber e descobrir o cuidado cultural, promovendo, assim, um tratamento adequado à realidade de sua clientela, ajudando-a a enfrentar o que for necessário. ${ }^{11}$ Nesse sentido, é essencial que respeitemos a cultura e os modos de vida das mães cuidadoras das crianças com asma, para que, ao longo do atendimento, possam ser preservados, acomodados e até mesmo reestruturados os seus valores. Essas três modalidades guiam as decisões ou ações do cuidado cultural para que este seja satisfatório, benéfico, coerente e significativo para os indivíduos que são atendidos por esses profissionais. ${ }^{13}$ É importante salientar que a enfermagem, assim como a mãe, pode buscar um cuidado melhor, e deve refletir sobre o cuidado profissional.

Durante a pesquisa, confirmamos a importância da socialização dos conhecimentos entre o enfermeiro e a clientela, mas é fundamental que este profissional saiba ouvir, para que consiga delinear estratégias preventivas que vão sendo construídas no decorrer do atendimento.

\section{REFERÊNCIAS}

1. Sociedade Brasileira de Pneumologia e Tisiologia. III Consenso brasileiro no manejo da asma. J Pneumol. 2002; 28( supp 1):S1-28.

2. Masoli M, Fabian D, Holt S, Beasley R. Global iniciative for asthma. Nova Zelândia: NIH e World Health Organization; 2003 dez 22.

3. Ministério da Saúde (BR) Departamento de Informática do SUS DATASUS. Informações de saúde epidemiológicas e morbidade. Indicadores de morbidade hospitalar por internação, 2008 [citado 25 abr 2009]. Disponível em: http://tabnet.datasus.gov.br/cgi/ tabcgi.exe?sih/cnv/niuf.def.

4. World Health Organization -WHO. Chronic respiratory diseases [on-line]. Genebra:WHO; 2007 [citado 13 jun 2008]. Disponível em: http://www.who.int/respiratory/asthma/causes/en/index.html.

5. Hockenberry MJ, Wilson D, Winkelstein M. Wong fundamentos da enfermagem pediátrica. $7^{\mathrm{a}}$ ed. Rio de Janeiro(RJ): Elsevier; 2006.

6. Secretaria de Estado da Saúde ( São Paulo). Educação em saúde: planejando as ações educativas: teoria e prática: manual para operacionalização das ações educativas no SUS. São Paulo (SP); 1997.

7. Badinter E. Um amor conquistado: o mito do amor materno. Tradução Waltensir Dutra. Rio de Janeiro (SP): Nova Fronteira; 1985.

8. Roehrs H, Lenardt MH, Maftum MA. Práticas culturais familiares e 0 uso de drogas psicoativas pelos adolescentes: reflexão teórica. Esc Anna Nery Rev Enferm 2008 jun; 12(2): 353-57.
A enfermagem deve desenvolver a sensibilidade para perceber as atitudes da mãe com relação à asma infantil e negociar o cuidado sem imposição, pois, se esta equipe de profissionais favorecer a manipulação dos seus princípios em detrimento dos valores culturais da mãe, poderá engendrar o descuido por parte delas, pois elas nem sempre têm condiç̃es sociais, econômicas e culturais para o melhor tratamento da asma de seu filho a partir do cuidado do subsistema de saúde profissional, e acabam utilizando apenas o embasamento do subsistema de saúde popular.

Madeleine Leininger fala sobre esse cuidado profissional formalmente ensinado, aprendido e transmitido, assim como 0 conhecimento de saúde, doença, bem-estar e as habilidades práticas que prevalecem em instituições profissionais e a grande necessidade de a atrelarmos com o saber popular para então prestarmos, de fato, um cuidado coerente com as necessidades do indivíduo.

A comunicação do conhecimento cultural é uma habilidade que a enfermeira profissional deve dominar. ${ }^{18}$ Diante disso, entendemos que se fazem necessários mais estudos sobre o cuidado cultural a fim de garantir a assistência individual e humanizada, respeitando a identidade cultural do indivíduo.

Em virtude do que foi exposto, reafirmamos a necessidade da enfermeira de entender a influência da cultura na dimensão do ser e que, para saber fazer o cuidado cultural em enfermagem, é necessário que haja uma contínua discussão e reflexão sobre a temática.

9. Leininger MM, McFarland RM. Cultural care diversity and universality: a worldwide nursing theory. $2^{\mathrm{a}}$ ed. Massachusetts (USA): Jones and Bartlett; 2006.

10. Lima LHO, Gomes EM, Braga VAB. Frequência de publicações sobre a asma em periódicos de enfermagem indexados em bases de dados brasileiros: uma revisão da literatura. Acta Paul Enferm [online] 2006 out/dez; [citado 16 maio 2008]; 19(4): [aprox.6 telas]. Disponivel em: http://www.scielo.br

11. Leininger MM. Transcultural care diversity and universality: theory of nursing. Nurs Health Care. 1985 abr; 6(4): 209-12.

12. Leininger MM. Etnonursing research studies to reflect uses of culture care theory. In: Culture care diversity and universality: a theory of nursing. Ney York (USA): National League for Nursing; 1991.

13. Ministério da Saúde (BR). Conselho Nacional de Saúde. Resolução $n^{0} 196$, de 10 outubro de 1996. Diretrizes e normas regulamentadoras de pesquisa envolvendo seres humanos. Brasília (DF); 1996.

14. Bosi DR. A criança asmática na família: estudo de uma representação [dissertação de mestrado] São Paulo (SP): Universidade de São Paulo; 1998.

15. Lima LHO, Carvalho ALB, Silva VM, Guedes MVC, Lopes MVO. Análisis del proceso de educación en salud para niños en estado asmático crítico. Tempus Vitalis [periódico na internet]. 2005; [citado 22 jun 2008]; 5(1): [aprox.7 telas]. Disponível em: 
http://www.tempusvitalis.com/descargas/articulos/2005vol5num1/ 2original51_1.pdf

16. Teixeira JJV, Lefréve F. Religiosidade no trabalho das enfermeiras da área oncológica: significado na ótica do discurso do sujeito coletivo. Rev Bras Cancerol. 2007; 53(2): 159-66.
17. Langdon EJ. 0 processo de ser saudável sob o ponto de vista antropológico [dissertação]. Florianópolis (SC): Centro de Ciências da Saúde/ UFSC; 1991.

18. Leininger MM. Human care and health series. Detroit (USA): Wayne State University Press; 1988. 